\title{
UMA ANÁLISE DE CONTEÚDOS DO BLOCO TRATAMENTO DA INFORMAÇÃO EM UM LIVRO DIDÁTICO DO 7º ANO DO ENSINO FUNDAMENTAL
}

\section{AN ANALYSIS OF CONTENTS OF THE BLOCK INFORMATION TREATMENT IN A TEACHING BOOK OF THE 7TH YEAR OF FUNDAMENTAL EDUCATION}

\author{
Camila Macedo Lima Nagamine ${ }^{1}$ \\ Jean Paixão Oliveira ${ }^{2}$ \\ Ana Paula Perovano ${ }^{3}$ \\ Cristina de Andrade Santos Reis ${ }^{4}$
}

\begin{abstract}
Resumo: Os conteúdos de estatística e probabilidade possuem grande relevância na educação básica possibilitando ao aluno recursos para uma leitura de sua sociedade e exercício consciente de sua cidadania. Como o livro didático possui um papel de destaque na atuação do professor, analisamos como um livro didático do $7^{\circ}$ ano aborda os conteúdos de estatística e probabilidade. Tivemos como aporte metodológico a pesquisa qualitativa. Nosso objetivo foi analisar o livro didático particularizando a análise global, regional e local. Do qual identificamos fragilidades no que tange a definições, conteúdos e habilidades. Esperamos contribuir no sentido de trazer reflexões sobre como vêm sendo apresentado o "Tratamento da Informação" nos livros didáticos evidenciando suas potencialidades e fragilidades.
\end{abstract}

Palavras-chave: Livro Didático; Ensino; Educação Estatística; Tratamento da Informação.

Abstract: The contents of statistics and probability have great relevance in basic education allowing the student resources for a reading of their society and conscious exercise of their citizenship. As the textbook has a prominent role in the teacher's performance, we analyze how a 7th grade textbook addresses the contents of statistics and probability. We had as methodological contribution the qualitative research. Our goal was to analyze the textbook, particularizing the global, regional and local analysis. Of which we identified weaknesses regarding definitions, content and skills. We hope to contribute to bring reflections on how the "Treatment of Information" has been presented in textbooks highlighting its potentialities and weaknesses.

Keywords: Textbook; Teaching; Statistical Education; Information Processing.

\footnotetext{
${ }^{1}$ Doutoranda do Programa de Pós-Graduação em Epidemiologia pela Universidade Federal do Rio Grande do Sul (UFRGS). Universidade Estadual do Sudoeste da Bahia (UESB), Vitória da Conquista, Bahia, Brasil. E-mail: camilanagamine@uesb.edu.br

${ }^{2}$ Mestrado em Educação Matemática pela Universidade Estadual de Santa Cruz (UESC). Secretaria Municipal de Amargosa, Amargosa, Bahia, Brasil. E-mail: jan26oliveira@ hotmail.com

${ }^{3}$ Doutoranda em Educação Matemática pela Universidade Estadual Paulista "Júlio de Mesquita Filho" (UNESP). Universidade Estadual do Sudoeste da Bahia (UESB), Vitória da Conquista, Bahia, Brasil. Email: apperovano@uesb.edu.br

${ }^{4}$ Especialista em Mídias na Educação pela UESB. Universidade Estadual do Sudoeste da Bahia (UESB), Vitória da Conquista, Bahia, Brasil. E-mail: cristina@uesb.edu.br
} 


\section{Introdução}

Os conteúdos de estatística e probabilidade possuem grande relevância na educação básica, pois podem constituir-se como "um recurso indispensável à cidadania ao instrumentalizar o cidadão com um conhecimento vinculado à realidade sócio-cultural que permita realizar uma leitura crítica no modelo de sociedade" (ARRUDA; MORETTI, 2002, p. 424).

Até meados dos anos 90 eram quase inexistentes inquietações a respeito do ensino dos conteúdos de estatística e probabilidade na educação básica. Com a publicação dos Parâmetros Curriculares Nacionais - PCN (BRASIL, 1997), foi destacada a necessidade de tais conteúdos se fazerem presente no currículo de matemática de modo a possibilitar que os alunos possam “'tratar” as informações que recebe cotidianamente, aprendendo a lidar com dados estatísticos, tabelas e gráficos, a raciocinar utilizando ideias relativas à probabilidade e à combinatória.” (BRASIL, 1997, p. 53). Surge, com este documento, os "Blocos de Conteúdos" da Matemática que incluíam o "Tratamento da Informação".

Atualmente temos, como diretrizes para o ensino de Matemática a Base Nacional Comum Curricular (2017) que recomenda "Unidades Temáticas" para o ensino da Matemática. Probabilidade e Estatística é a unidade temática que abordará a incerteza e o tratamento de dados.

Mesmo com o reconhecimento da importância do ensino de Estatística e Probabilidade e com a sua inserção nos documentos oficiais desde 1997, o que vemos em nossa prática diária é que a abordagem destes conteúdos tem sido deixada para o final do ano letivo e "nem sempre [são] estudados pelos alunos, por falta de tempo, por falta de convicção do seu real interesse ou por falta de domínio teórico-metodológico do professor sobre os conceitos estatísticos e probabilísticos." (LOPES, 2010, p. 58).

Como "a grande maioria dos educadores atribui ao livro um papel de destaque entre os recursos didáticos que podem ser utilizados" (BRASIL, 2017a, p. 13), consideramos que é preciso "ter cuidado na sua escolha, pois é preciso verificar os conteúdos abordados, sua didática e sua organização, de forma a poder balancear os temas selecionados, para que alguns não fiquem prejudicados em favor dos outros" (VIALI; OLIVEIRA, 2010, p. 86). Nessa perspectiva analisamos como um livro didático do $7^{\circ}$ ano do Ensino Fundamental aborda os conteúdos de estatística e probabilidade. 
DOI: http://dx.doi.org/10.33238/ReBECEM.2019.v.3.n.2.22439

\section{A Educação Estatística e os Documentos Oficiais para o Ensino de Matemática}

Ao falarmos em Estatística, a princípio, pensamos em gráficos, tabelas, quantidades numéricas, média, moda, desvio padrão. No entanto, o significado dessa palavra toma outras dimensões além do que estamos acostumados a presenciar por meio da TV, jornais e revistas.

Cazorla, Kataoka e Silva (2010) entendem a Estatística como:

Uma ciência que tem como objetivo desenvolver métodos para coletar, organizar e analisar dados. Já a Educação Estatística é uma nova área de pesquisa que nasceu na década de 1970. [...] e tem como objetivo estudar e compreender como as pessoas ensinam e aprendem Estatística, visando o desenvolvimento do letramento estatístico (CAZORLA; KATAOKA; SILVA, 2010, p. 22, grifo das autoras).

Conforme mencionamos acima, os estudos acerca da Educação Estatística, começaram a ter destaque na década de 90 com a publicação dos PCN que trata destes temas no bloco de conteúdo Tratamento da Informação.

Sobre à Estatística, estes documentos oficiais apontam que:

[...] a finalidade é fazer com que o aluno venha a construir procedimentos para coletar, organizar, comunicar dados, utilizando tabelas, gráficos e representações que aparecem frequentemente em seu dia-a-dia. Além disso, calcular algumas medidas estatísticas como média, mediana e moda com o objetivo de fornecer novos elementos para interpretar dados estatísticos (BRASIL, 1998, p. 52).

Dessa forma, entendemos que a finalidade da Estatística, segundo o referido documento, é prover o aluno de habilidades para exercer a "leitura" de dados estatísticos, além da compreensão de como interpretar os conteúdos de Estatística e de Probabilidade no nosso cotidiano.

Apresentamos, de acordo com os PCN, as orientações dispostas no bloco Tratamento da Informação:

Coleta, organização de dados e utilização de recursos visuais adequados (fluxogramas, tabelas e gráficos) para sintetizá-los, comunicá-los e permitir a elaboração de conclusões;

Leitura e interpretação de dados expressos em tabelas e gráficos;

Compreensão do significado da média aritmética como um indicador da tendência de uma pesquisa;

Representação e contagem dos casos possíveis em situações combinatórias; Construção do espaço amostral e indicação da possibilidade de sucesso de um evento pelo uso de uma razão (BRASIL, 1998, p. 74).

Nessa perspectiva, ao se trabalhar com coleta e organização de dados, bem como, leitura, construção e interpretação de tabelas e gráficos como exposto no bloco Tratamento da Informação, para o ensino de Estatística, percebemos a importância de 
DOI: http://dx.doi.org/10.33238/ReBECEM.2019.v.3.n.2.22439

promover projetos que levem em conta a realidade local dos estudantes e das nossas instituições de ensino de maneira contextualizada. Esses dados podem ser coletados pelos próprios alunos na escola ou em casa, o professor pode construir junto à turma um banco de dados, com informações de peso, altura, tamanho dos calçados, gênero, idade, mês de nascimento, personagem favorito, números de irmãos, nível de escolaridade dos pais, local onde reside, consumo de água $\left(\mathrm{em} \mathrm{m}^{3}\right)$.

A construção e discussão de banco de dados e de gráficos e tabelas, facilita para os alunos, a compreensão do significado da média aritmética, da moda e da mediana, como indicadores de medidas de tendência central. Ainda nesse sentido, os documentos oficiais abordam questões sobre a importância do envolvimento das questões sociais e da integração com outras áreas do conhecimento. Assim, os PCN de Matemática, apontam que:

\begin{abstract}
Uma forma de explorar os processos estatísticos e probabilísticos é a partir da leitura e discussão das informações que aparecem nos jornais. Nesse trabalho a calculadora é um instrumento imprescindível porque os cálculos são muitos e costumam ser trabalhosos em virtude dos números envolvidos, revistas, rádio, televisão, Internet etc. Assuntos que tratam de economia, política, esportes, educação, saúde, alimentação, moradia, meteorologia, pesquisas de opinião, entre outros, geralmente são apresentados por meio de diferentes representações gráficas: tabelas, diagramas e fluxogramas, gráficos (barras, setores, linhas, pictóricos, histogramas e polígonos de frequência). Além disso, tais assuntos costumam despertar o interesse dos alunos pelas questões sociais e podem ser usados como contextos significativos para a aprendizagem dos conceitos e procedimentos matemáticos neles envolvidos. Constituem-se também num campo de integração com os conteúdos de outras áreas do currículo, como os das Ciências Sociais e Naturais e, em particular, com as questões tratadas pelos Temas Transversais (BRASIL, 1998, p. 134).
\end{abstract}

Nesse âmbito, percebemos a importância em se trabalhar os conteúdos abordados no bloco Tratamento da Informação, e para isso, os documentos oficiais nos apontam diversos recursos como por exemplo história da Matemática, uso de tecnologias da comunicação e jogos. Os PCN apontam também as facilidades em se trabalhar com os temas transversais por meio dos dados estatísticos, pois os conteúdos do bloco Tratamento da Informação "fornecem instrumentos necessários para coletar e organizar as informações, interpretá-las, fazer cálculos e desse modo produzir argumentos para fundamentar conclusões sobre elas" (BRASIL, 1998, p. 29).

Para além dos Parâmetros, foi lançada em 2017 a BNCC que tem por "objetivo traçar recursos de aprendizagem e desenvolvimento dos estudantes da educação básica, ou seja, ao longo da educação infantil, do ensino fundamental e ensino médio" (BRASIL, 2017b). 
DOI: http://dx.doi.org/10.33238/ReBECEM.2019.v.3.n.2.22439

De acordo com a BNCC, a unidade temática Probabilidade e Estatística propõe uma abordagem dos conceitos, fatos e procedimentos presentes em muitas situações da vida cotidiana.

Ela propõe a abordagem de conceitos, fatos e procedimentos presentes em muitas situações-problema da vida cotidiana, das ciências e da tecnologia. Assim, todos os cidadãos precisam desenvolver habilidades para coletar, organizar, representar, interpretar e analisar dados em uma variedade de contextos, de maneira a fazer julgamentos bem fundamentados e tomar as decisões adequadas. Isso inclui raciocinar e utilizar conceitos, representações e índices estatísticos para descrever, explicar e predizer fenômenos. Merece destaque o uso de tecnologias - como calculadoras, para avaliar e comparar resultados, e planilhas eletrônicas, que ajudam na construção de gráficos e nos cálculos das medidas de tendência central. A consulta a páginas de institutos de pesquisa - como a do Instituto Brasileiro de Geografia e Estatística (IBGE) - pode oferecer contextos potencialmente ricos não apenas para aprender conceitos e procedimentos estatísticos, mas também para utilizá-los com o intuito de compreender a realidade. (BRASIL, 2017b, p. 276).

Tal como os PCN, a BNCC reforça a utilização das tecnologias no ensino de tais conteúdos em sala de aula. Há a sugestão da página do IBGE como contexto para abordar conceitos e procedimentos da estatística e da probabilidade o que permite ao aluno compreender a sua realidade possibilitando um acesso a informações reais o que permite que ele possa exercitar, de forma consciente, a sua cidadania.

Para além dos referidos documentos, os grupos de pesquisas (GT 12 da $\mathrm{SBEM}^{4}$, Grupo de Pesquisa em Educação Estatística ${ }^{5}$, Grupo de Estudos e Pesquisa em Educação Estatística $^{6}$, Grupo de Pesquisa em Educação Matemática, Estatística e ciências ${ }^{7}$, entre outros) têm se preocupado em debater o que ensinar e como ensinar Estatística, priorizando objetivos e propostas sugeridas pelos PCN. Outrossim, Jacobini, Wodewotzki e Campos (2011) destacam alguns objetivos da Educação Estatística:

\footnotetext{
Promover o entendimento e o avanço da Educação Estatística seus assuntos correlacionados;

Fornecer embasamento teórico às pesquisas em Ensino de Estatística; Melhorar a compreensão das dificuldades dos estudantes;

Estabelecer parâmetros para um ensino mais eficiente dessa disciplina; Auxiliar o trabalho do professor na construção de suas aulas;
}

\footnotetext{
${ }^{4}$ Criado em 2001, discute o ensino de Estatística e Probabilidade.

${ }^{5}$ GPEE, criado em 2004 e vinculado a UNESP, campos Rio Claro.

${ }^{6}$ GEPEE, Grupo organizado em 2009 vinculado a UNICSUL-SP

${ }^{7}$ GPEMEC, vinculado a Universidade Estadual de Santa Cruz, na Bahia.
} 
DOI: http://dx.doi.org/10.33238/ReBECEM.2019.v.3.n.2.22439

Sugerir metodologias de avaliação diferenciadas, centradas em metas estabelecidas e em competências a serem desenvolvidas;

Valorizar uma postura investigativa, reflexiva e crítica do aluno, em uma sociedade globalizada, marcada pelo acúmulo de informações e pela necessidade de tomada de decisões em situações de incerteza (2011, p.12).

Tais objetivos propostos por estudiosos da Educação Estatística buscam garantir ao campo da pesquisa, métodos e parâmetros para melhor compreensão das dificuldades dos alunos no que tange ao conteúdo Estatística, bem como, procura dar suporte aos professores na construção de suas aulas, buscando competências para o letramento estatístico.

De acordo com os objetivos propostos pela Educação Estatística, Garfield e Gal (1999) propõem algumas metas:

Entender o propósito e a lógica das investigações estatísticas;

Entender o processo de investigação estatística;

Dominar as habilidades usadas nos processos de investigação estatística;

Entender as relações matemáticas presentes nos conceitos estatísticos;

Desenvolver habilidades interpretativas para argumentar, refletir e criticar;

Desenvolver habilidades para se comunicar estatisticamente, usando corretamente a sua termologia;

Desenvolver habilidades colaborativas e corporativas para trabalhar em equipe;

Desenvolver hábitos de questionamentos dos valores, grandezas e dados e informações (GARFIELD; GAL, 1999, s.p.).

Nessa perspectiva, almejamos o desenvolvimento dos alunos no que diz respeito à capacidade de pensar criticamente sobre as situações propostas, bem como, explicar tais situações, relacionar dados, refletir sobre as informações e apresentação dos dados.

Partindo dos assuntos a serem trabalhados ao longo dos anos iniciais do Ensino Fundamental e levando em consideração os objetivos propostos pela Educação Estatística, pelos PCN e pela BNCC, além das metas apontadas por Garfield e Gal (1999) apresentaremos o quadro 1, no qual expomos os conteúdos a serem ministrados ao se ensinar Estatística.

Quadro 1: Conteúdos de Estatística, segundo os PCN, para os $3^{\circ}$ e $4^{\circ}$ ciclos do Ensino Fundamental II

\begin{tabular}{|c|l|l|}
\hline $\begin{array}{c}\text { Conteúdos } \\
\begin{array}{c}\text { Conceituais e } \\
\text { Procedimentais }\end{array}\end{array}$ & \multicolumn{1}{|c|}{$\mathbf{3}^{\mathbf{0}}$ ciclo } & \multicolumn{1}{c|}{$\mathbf{4}^{\mathbf{0}}$ ciclo } \\
\hline & $\begin{array}{l}\text { Leitura, construção e interpretação de } \\
\text { dados expressos em tabelas e gráficos } \\
\text { de barra, de setores e pictogramas. }\end{array}$ & $\begin{array}{l}\text { Leitura, construção e interpretação de } \\
\text { dados expressos em tabelas e gráficos de } \\
\text { barra, de setores e pictogramas e } \\
\text { segmentos. }\end{array}$ \\
$\begin{array}{c}\text { Variáveis, } \\
\text { Frequências e } \\
\text { Gráficos. }\end{array}$ & $\begin{array}{l}\text { Coletar, organizar e utilização de } \\
\text { recursos visuais adequados. } \\
\text { (Fluxogramas, tabelas e gráficos) }\end{array}$ & $\begin{array}{l}\text { Organização de dados e construção de } \\
\text { recursos visuais adequados. (Gráficos, } \\
\text { histogramas e polígonos de frequência) }\end{array}$ \\
\cline { 2 - 3 }
\end{tabular}


DOI: http://dx.doi.org/10.33238/ReBECEM.2019.v.3.n.2.22439

\begin{tabular}{|c|c|c|}
\hline & & $\begin{array}{l}\text { Compreensão de termos como } \\
\text { frequência, frequência relativa e amostra } \\
\text { de uma população. }\end{array}$ \\
\hline & & $\begin{array}{l}\text { Identificar e classificar as variáveis em } \\
\text { quantitativa e qualitativa. }\end{array}$ \\
\hline \multirow{2}{*}{$\begin{array}{l}\text { Medidas de } \\
\text { Tendência Central }\end{array}$} & \multirow{2}{*}{$\begin{array}{l}\text { Organização dos dados em rol. } \\
\text { Compreensão do significado da } \\
\text { média, da moda e da mediana como } \\
\text { um indicador da tendência de uma } \\
\text { pesquisa. }\end{array}$} & $\begin{array}{l}\text { Compreensão dos significados da média, } \\
\text { mediana e moda. }\end{array}$ \\
\hline & & $\begin{array}{l}\text { Distribuir os dados em intervalos de } \\
\text { classe. }\end{array}$ \\
\hline \multirow[t]{2}{*}{$\begin{array}{l}\text { Espaço amostral e } \\
\text { definição de } \\
\text { probabilidades. }\end{array}$} & \multirow[t]{2}{*}{$\begin{array}{l}\text { Construção de espaço amostral e } \\
\text { indicação da possibilidade de } \\
\text { sucesso de um evento pelo uso de } \\
\text { uma razão. }\end{array}$} & $\begin{array}{l}\text { Construção do espaço amostral, } \\
\text { utilizando o princípio multiplicativo } \\
\text { e a indicação da probabilidade de um } \\
\text { evento por meio da razão. }\end{array}$ \\
\hline & & $\begin{array}{lcr}\text { Elaboração } & \text { de } & \text { experimentos } \\
\text { simulações } & \text { para } & \text { estimar } \\
\text { probabilidades } & \text { e } & \text { verificar } \\
\text { probabilidades previstas. } & \end{array}$ \\
\hline
\end{tabular}

Fonte: Adaptado de Cazorla e Santana (2010, p.11)

De acordo com o Quadro 1 podemos perceber de forma detalhada os conteúdos a serem trabalhados em cada ciclo dos anos finais do Ensino Fundamental, que direcionou nossa análise do livro didático, pois verificaremos, dentre outros aspectos, se o livro analisado apresenta os conteúdos sugeridos pelos PCN. O nosso trabalho terá foco no terceiro ciclo, $7^{\circ}$ ano.

\section{Aspectos Metodológicos}

O presente trabalho enquadra-se numa abordagem qualitativa, pois tem como objetivo analisar de que forma o livro didático selecionado, do $7^{\circ}$ ano aborda os conteúdos de Estatística e Probabilidade.

A presente pesquisa atende as características da pesquisa qualitativa, pois o problema de pesquisa a ser investigado sugere uma análise descritiva e explicativa dos dados expressos no livro didático. Além disso, os pesquisadores preocupam-se com a descrição dos dados promovendo seu significado. No que tange a pesquisa qualitativa podemos destacar algumas técnicas de coleta de dados: análise documental, entrevista, observação. Para esta pesquisa utilizaremos a análise documental como técnica de coleta de dados.

O documento utilizado nesta pesquisa foi o livro didático do $7^{\circ}$ ano da coleção "Vontade de Saber", nele particularizamos a análise global, regional e local tendo como referência os estudos de Henriques, Nagamine e Nagamine (2012), que consideram estas estruturas como apresentado na Figura 1. 
Figura 1: Estrutura organizacional do livro didático

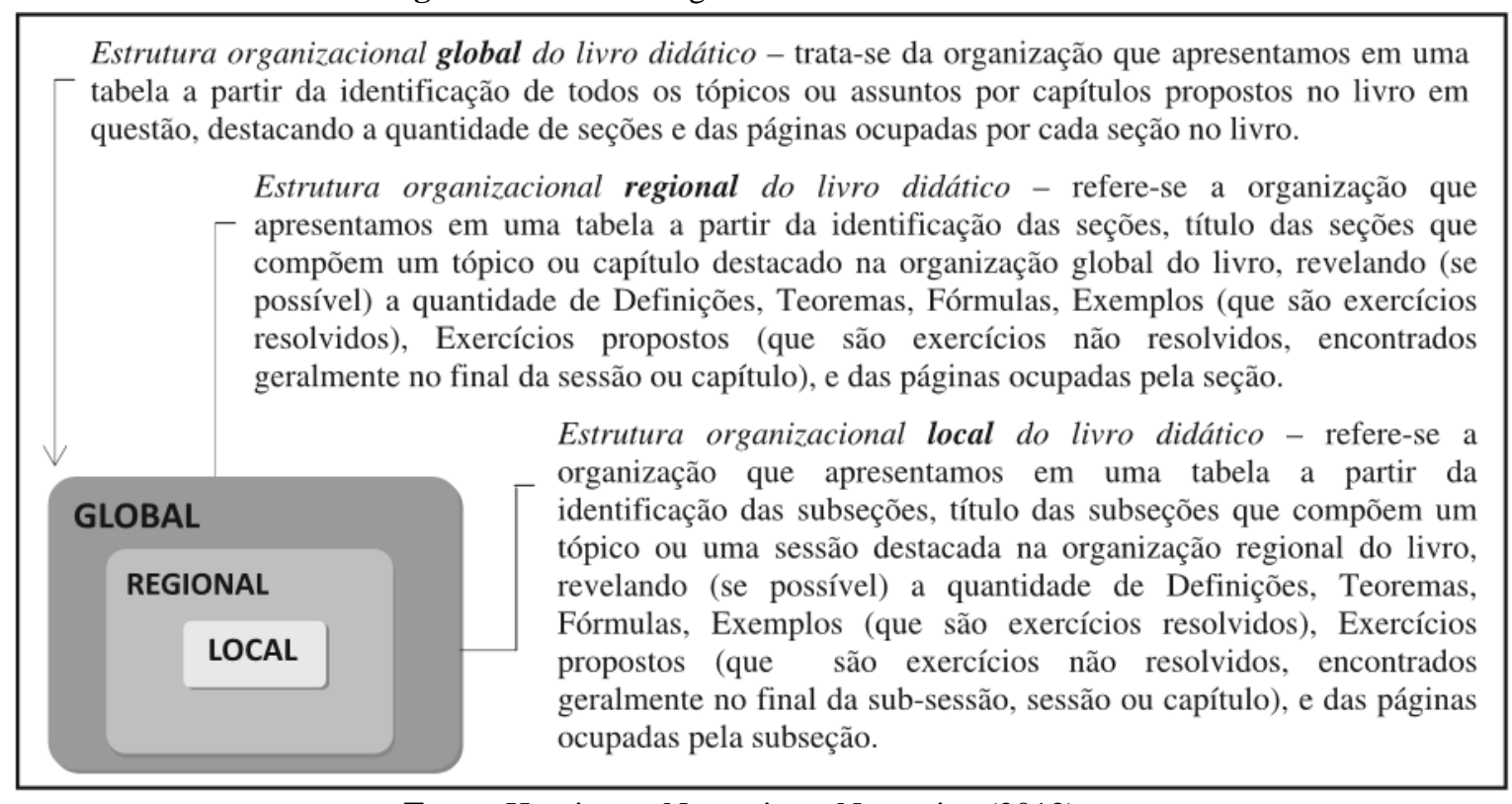

Fonte: Henriques, Nagamine e Nagamine (2012)

De acordo com a Figura 1 abordaremos a estrutura do livro, Vontade de Saber Matemática, por meio da estrutura global, regional e local.

Utilizamos essas estruturas com o propósito de obtermos uma análise geral dos objetos de estudo relacionados aos conteúdos de Estatística e Probabilidade propostos na obra citada.

A análise dos dados para o desenvolvimento desta pesquisa foi inspirada na Teoria Fundamentada (CHARMAZ, 2009), fazendo uso dos métodos comparativos para estabelecer distinções e realizar comparações entre o que é posto nos $\mathrm{PCN}$ e no livro didático analisado. A codificação linha a linha auxiliou na primeira leitura dos dados, e a partir da análise desses dados encontramos evidências teóricas para descrever o que é proposto pelos PCN e o que é abordado no livro didático.

Optamos em criar categorias com o intuito de apresentarmos e analisarmos os dados extraídos do documento (livro didático). No que se refere às categorias de análise, nos apoiamos nos estudos de Fiorentini e Lorenzato (2007) que apontam essas categorias como um procedimento de classificação das informações, destacando elementos que devem ser considerados pelo pesquisador. Os autores apontam três tipos de categorias, são elas:

(1) definidas a priori, quando o pesquisador vai a campo com categorias previamente estabelecidas, podendo ser ou não provenientes da literatura; (2) emergentes, quando são obtidas, mediante um processo interpretativo, diretamente do material de campo; (3) ou mistas, quando o pesquisador obtém as características a partir de um confronto entre o que diz a literatura e o que 


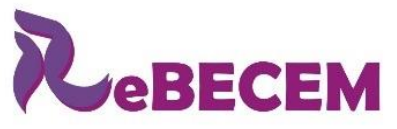

Revista Brasileira de Educação em

Ciências e Educação Matemática

DOI: http://dx.doi.org/10.33238/ReBECEM.2019.v.3.n.2.22439

encontra nos registros de campo. (FIORENTINI; LORENZATO, 2007, p. 135, grifo do autor).

Nesse sentido, para a nossa análise utilizamos das categorias definidas. Ao analisarmos o livro didático já tínhamos em mente as categorias que iriamos utilizar, a saber: a análise global, regional e local.

\section{Resultados e Discussões}

Antes de adentrarmos em nossas categorias vamos apresentar nosso objeto de estudo qual seja, o livro Vontade de Saber Matemática (SOUZA; PATARO, 2015). Os conteúdos voltados ao bloco Tratamento da Informação estão presentes em toda coleção, no entanto, utilizamos como fonte de dados para este texto apenas o livro do $7^{\circ}$ ano. A escolha pelo livro e pelo ano escolar justifica-se por ser o livro e o ano escolar em que uma das autoras utiliza e atua escola.

Figura 2: Capa do livro didático

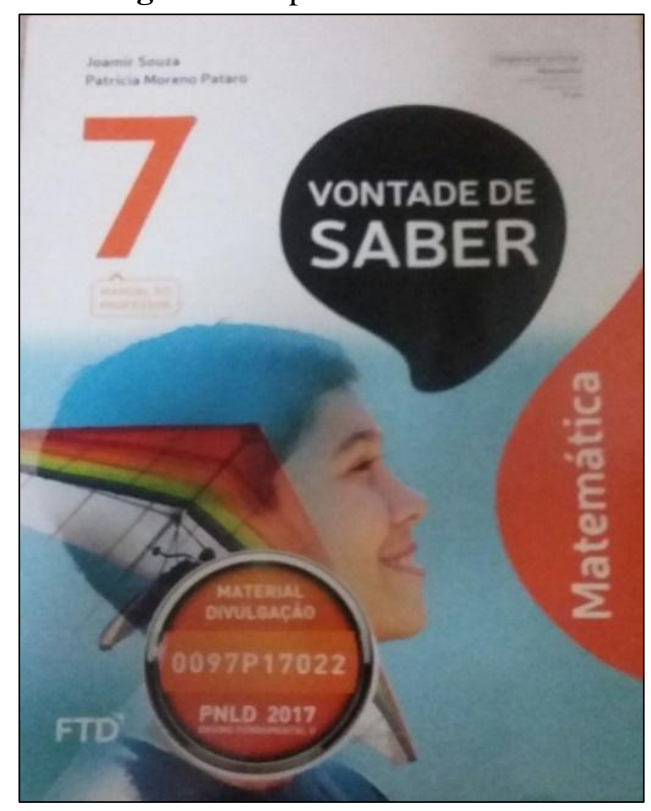

Fonte: Souza e Pataro (2015)

O livro é composto por imagens e representações gráficas. As imagens são constituídas de fotos de personagens que dialogam com o conteúdo abordado, inseridos dentro de um contexto. Outras figuras relacionadas aos conteúdos são expostas no decorrer de todo o livro didático buscando uma aproximação entre conteúdo e ilustrações, que são adequadas à faixa etária dos alunos que provavelmente usarão o livro analisado. O livro aborda figuras relacionadas a outras disciplinas como mapas, animais, dados históricos etc. 
DOI: http://dx.doi.org/10.33238/ReBECEM.2019.v.3.n.2.22439

Todos os conteúdos são iniciados com um texto, que trata sobre o assunto a ser abordado em contexto com a realidade, por exemplo, o capítulo Tratamento da Informação é iniciado com um texto que aborda avanços nos meios de comunicação por meio da internet, na sequência o autor traz diversos gráficos que mostram os índices de adesão às redes sociais nos últimos anos. Na sequência promove uma discussão acerca desses dados, buscando promover uma ação reflexiva dos alunos e aproximá-los dos conteúdos a serem estudados mais a frente, a saber: gráficos e tabelas, medidas de tendência central e probabilidade.

Os capítulos são compostos de uma seção intitulada desafio, nela é posta um desafio $^{8}$ relacionado aos conteúdos estudados ao longo do capítulo. Destacamos também a inclusão de informes ao longo do livro, por exemplo, ao aparecer a figura de um computador, os autores abordam dados como ano de criação e seu criador e todas as informações contidas, como a indicação de links para pesquisas, são escritas em uma linguagem acessível ao público ao qual o livro se destina. Além disso, recortes de jornais e revistas aparecem em todos os capítulos, sempre nas primeiras e últimas páginas, objetivando uma contextualização do conteúdo.

Os textos abordados na introdução e na conclusão de cada capítulo normalmente são extraídos e resumidos da internet com sugestão do site para o aluno que desejar obter mais informações sobre o assunto abordado no texto.

No decorrer do livro não notamos indicações de livros ou textos complementares aos conteúdos, mas ao final os autores fazem indicações de trinta livros paradidáticos que podem ser lidos como complemento aos conteúdos trabalhados, dos quais, apenas um se refere aos conteúdos relacionados ao bloco Tratamento da Informação. Além disso, dispõe de quatorze links de sites onde podemos encontrar vídeos, exercícios, desafios e textos, desses, um faz referência aos conteúdos do bloco Tratamento da Informação.

O livro analisado dispõe de uma grande quantidade de atividades em cada capítulo, muitas dessas partem de um problema situado dentro da semirealidade ${ }^{9}$ dos alunos, outras são trabalhadas no contexto da Matemática pela Matemática, e trazem em seus enunciados apenas, calcule, efetue, resolva. Nessa coleção é comum encontrar atividades que trabalham algum conceito específico não trabalhado ao longo do capítulo.

\footnotetext{
8 “Atividades que possuem caráter desafiador, nas quais você é estimulado desenvolver suas próprias estratégias para a resolução" (SOUZA; PATARO, 2015).

${ }^{9}$ Comungamos com Skovsmose (2000) e consideramos semirealidade com algo que não se trata de uma realidade de fato, mas uma realidade fictícia, ou seja, a situação é artificial.
} 


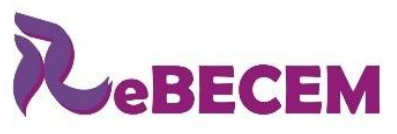

Revista Brasileira de Educação em

Ciências e Educação Matemática

DOI: http://dx.doi.org/10.33238/ReBECEM.2019.v.3.n.2.22439

Destacamos que quando isso acontece os autores propõem uma questão resolvida e em seguida algumas atividades similares a questão resolvida. De modo geral os exercícios possibilitam apenas a aplicação de conceitos previamente trabalhados.

\subsection{Organização global do livro didático}

Na estrutura global destacamos alguns aspectos, são eles: i) abertura do capítulo; ii) conteúdo; iii) atividades; iv) refletindo sobre o capítulo; V) ser consciente; vi) revisão; vii) Resolvendo problemas; viii) ENEM e OBMEP ${ }^{10}$.

$\mathrm{Na}$ abertura do capítulo, os autores, apresentam duas páginas de textos referentes aos conteúdos a serem trabalhados. Nelas há informações que se referem a outras áreas do conhecimento, apresentadas por meio de texto, fotografias, esquemas, gráficos entre outros. Além disso, os autores apresentam questões com teor reflexivo que tem como objetivo "resgatar o conhecimento prévio do aluno e estabelecer intuitivamente relações entre o assunto abordado e alguns conteúdos matemáticos" (SOUZA; PATARO, 2015, p. 326).

Acreditamos que é essencial considerar o resgate de conhecimento prévio, uma vez que a consolidação do conhecimento não deve ser feita de maneira fragmentada, pois a concessão com conhecimentos/habilidades anteriores induz à identificação das aprendizagens já consolidadas, proporcionando o desenvolvimento de habilidades para as aprendizagens futuras.

A abertura do capítulo 5, onde foi realizada a análise local, é composta por um texto falando sobre pesquisas de opinião realizado pelo IBGE. O texto aborda a pesquisa por amostra e os diversos recursos tecnológicos utilizados para facilitar as atuais pesquisas. Na abertura do capítulo fica em destaque a imagem de um computador de mão utilizado no censo demográfico realizado pelo IBGE em 2010.

No que se refere ao item conteúdo, são apresentados em tópicos variando entre 2 e 8 tópicos em cada capítulo. Em cada tópico de conteúdos existem seções de Atividades.

As atividades são referentes aos conteúdos abordados em um ou mais tópicos de cada capítulo. De acordo com os autores do livro as atividades são organizadas em nível crescente de dificuldade (SOUZA; PATARO, 2015). No que tange à seção Revisão, que

\footnotetext{
${ }^{10}$ ENEM - Exame Nacional do Ensino Médio

OBMEP - Olímpiadas Brasileira de Matemática das Escolas Públicas
} 
DOI: http://dx.doi.org/10.33238/ReBECEM.2019.v.3.n.2.22439

aparece ao final de cada capítulo, é constituída de atividades que podem ser trabalhadas em grupos, em casa ou como complemento avaliativo.

Após a última atividade de cada capítulo o livro aborda uma seção intitulada refletindo sobre o capítulo, que segundo Souza e Pataro (2015) oportunizam o aluno a refletir sobre o conteúdo estudado, explicitando as ideias principais por meio de questionamentos, com o intuito de fazer uma auto avaliação.

A seção ser consciente faz parte de alguns capítulos do livro analisado e "tem o objetivo de trabalhar assuntos relacionados a temas como educação, sustentabilidade e ética" (SOUZA; PATARO, 2015, p. 327). Destacamos que a seção supracitada não faz parte do capítulo Tratamento da Informação, no livro analisado. Essa seção se inicia com uma história em quadrinhos que aborda a situação do dia a dia de uma determinada família, seguido de um texto complementar ao tema e por fim algumas questões a serem resolvidas e discutidas pelos alunos. Nos capítulos onde não se têm a seção ser consciente os autores colocam em seu lugar a seção resolvendo problema. Em capítulo tem uma seção ou outra, nunca as duas.

Em resolvendo problema é apresentado um problema selecionado de edições anteriores do Exame Nacional do Ensino Médio - ENEM, em que a resolução está de acordo com o conteúdo trabalhado. Segundo Souza e Pataro (2015, p. 328) "essa seção foi inspirada no recurso didático Resolução de Problemas, e são propostas etapas para se conduzir a resolução das atividades."

De acordo com Souza e Pataro (2015, p. 328), as seções ENEM e Olimpíadas Brasileiras de Matemática das Escolas Públicas - OBMEP "são atividades de múltiplas escolhas que foram elaboradas ou selecionadas do ENEM ou das OBMEP."

Disposta ao final do livro, na seção Acessando a tecnologia, traz indicações de recursos como sites e softwares, bem como exercícios relacionados aos conteúdos que podem ser resolvidos utilizando os sites e softwares sugeridos. Enfatizamos que esse tópico, apresenta uma grande oportunidade para os professores e alunos conhecerem e aplicar a estatística utilizando as novas tecnologias como é o caso do Software livre GeoGebra e Excel.

O objetivo dessa seção é "estabelecer uma estratégia de ensino complementar à apresentada no livro texto" (SOUZA; PATARO, 2015, p. 329). Por fim, a seção ampliando seus conhecimentos que também se encontra no final do livro, os autores trazem sugestões de livros e sites para que os alunos possam complementar os estudos dos conteúdos visto ao longo do livro didático. 
DOI: http://dx.doi.org/10.33238/ReBECEM.2019.v.3.n.2.22439

O Quadro 2 apresenta a estrutura organizacional global do livro didático analisado. Nele podemos observar a quantidade de capítulos, número de seções e de páginas por capítulos.

Quadro 2: Estrutura organizacional global do livro didático

\begin{tabular}{|l|l|l|l|}
\hline Capítulos & Conteúdos & Seções $^{\mathbf{1 1}}$ & Páginas \\
\hline $\mathbf{1}$ & Funções & 12 & 30 \\
\hline $\mathbf{2}$ & Números decimais & 10 & 26 \\
\hline $\mathbf{3}$ & $\begin{array}{l}\text { Formas geométricas } \\
\text { decimais }\end{array}$ & 6 & 14 \\
\hline $\mathbf{4}$ & $\begin{array}{l}\text { Números positivos e } \\
\text { números negativos }\end{array}$ & 10 & 42 \\
\hline $\mathbf{5}$ & $\begin{array}{l}\text { Tratamento da } \\
\text { informação }\end{array}$ & 24 \\
\hline $\mathbf{6}$ & $\begin{array}{l}\text { Expressão algébrica, } \\
\text { fórmulas e equações }\end{array}$ & 7 & 18 \\
\hline $\mathbf{7}$ & $\begin{array}{l}\text { Grandezas enidades } \\
\text { de medidas }\end{array}$ & 6 & 22 \\
\hline $\mathbf{8}$ & Ângulos de & 6 & 24 \\
\hline $\mathbf{9}$ & Polígonos & 7 & 14 \\
\hline $\mathbf{1 0}$ & Proporcionalidade & 8 & 26 \\
\hline $\mathbf{1 1}$ & $\begin{array}{l}\text { Transformação } \\
\text { figuras e simetria }\end{array}$ & 16 \\
\hline $\mathbf{1 2}$ & Medidas de volume & 6 & 12 \\
\hline & Acessando tecnologias & & 14 \\
\hline & $\begin{array}{l}\text { Ampliando } \\
\text { conhecimentos seus }\end{array}$ & & 16 \\
\hline & Respostas & Bibliografia & 1 \\
\hline & & 5 & 24 \\
\hline
\end{tabular}

Fonte: Elaborado pelo autor - dados da pesquisa

De acordo com o Quadro 2 percebemos uma predominância nos assuntos voltados aos blocos Números e Operações e ao bloco Espaço e Forma.

\subsection{Organização regional do livro didático}

Cada capítulo contém em média 22 páginas. Nessa circunstância existem seis capítulos com páginas acima da média e cinco capítulos abaixo da média da quantidade de páginas. É perceptível que o maior capítulo se refere aos números positivos e negativos (Cap.4) e o menor, medidas de volume (Cap. 12).

De acordo com a Figura 2, apresentamos a organização regional do livro didático em forma de tabela. Nessa organização regional consideraremos o capítulo 5 intitulado Tratamento da Informação composto por 6 seções e 26 páginas. Abaixo temos o Quadro 3 no qual apresentamos a estrutura organizacional do capítulo.

\footnotetext{
${ }^{11}$ As atividades que constam ao final de cada seção de conteúdos não foram consideradas com seção.
} 


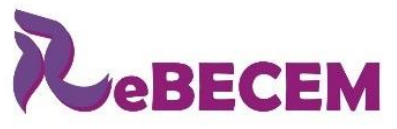

Revista Brasileira de Educação em

Ciências e Educação Matemática

DOI: http://dx.doi.org/10.33238/ReBECEM.2019.v.3.n.2.22439

Quadro 3: Estrutura organizacional regional do livro didático

\begin{tabular}{|c|c|c|c|c|}
\hline Seção & Definições & Exemplos & Atividades & Páginas \\
\hline $\begin{array}{l}\text { Abertura do } \\
\text { capítulo }\end{array}$ & 0 & --- & 3 & 2 \\
\hline Gráficos e tabelas & $1^{12}$ & 2 & 4 & 3 \\
\hline $\begin{array}{l}\text { Construção de } \\
\text { gráfico de setores }\end{array}$ & 0 & 1 & 2 & 2 \\
\hline Média aritmética & 1 & 1 & 2 & $\frac{1}{2}$ \\
\hline Média ponderada & 0 & 1 & 3 & 1 \\
\hline Possibilidades & 0 & 2 & 7 & 4 \\
\hline Probabilidade & 0 & 2 & 7 & 3 \\
\hline $\begin{array}{l}\text { Refletindo sobre o } \\
\text { capítulo }\end{array}$ & & --- & 8 & $\frac{1}{2}$ \\
\hline Revisão & & --- & 12 & 2 \\
\hline $\begin{array}{l}\text { Resolvendo } \\
\text { problemas }\end{array}$ & & --- & 14 & 2 \\
\hline ENEM e OBMEP & & --- & 7 & 2 \\
\hline
\end{tabular}

Fonte: Elaborado pelo autor - dados da pesquisa

Por meio da análise regional podemos perceber que o livro dispõe de duas páginas para a abertura do capítulo, a qual aborda um texto referente a pesquisas de opinião, seguido de alguns questionamentos relacionados ao texto que foram extraídos da internet e acessado em abril de 2015.

Na sequência os autores iniciam o conteúdo, por meio da seção gráficos e tabelas, nela os autores abordam exemplo reais, extraídos da internet e com fotos para ilustração e um melhor entendimento. Na sequência abordam um box de atividades. As seções de conteúdo, seguindo essa mesma linha se repete por meio das seguintes seções: construção de gráficos de setores; média aritmética; média ponderada; possibilidade e probabilidade.

Na seção refletindo sobre o capítulo, os autores apresentam oito questões nas quais os alunos são convidados a refletirem sobre os conteúdos estudados. Segundo Souza e Pataro (2015, p. 327) essa seção "oferece aos alunos a oportunidade de refletir sobre o conteúdo estudado, explicitando as ideias principais por meio de questionamentos com o objetivo de fazer uma autoavaliação."

No que se refere à revisão, o capítulo em destaque dispões de 12 atividades, dessas 8 apresentam subatividades, destacamos ainda que das 12 nenhuma delas é de múltipla escolha. Nesta seção as atividades podem ser trabalhadas de diversas maneiras, individual ou grupo, na própria sala de aula (SOUZA; PATARO, 2015, p. 328).

Para o capítulo Tratamento da Informação os autores adotaram a seção resolvendo problemas, constituída a partir de um problema extraído do Exame Nacional do Ensino Médio - ENEM e que tem por objetivo identificar dentre as vacas apresentadas na tabela

\footnotetext{
${ }^{12}$ A definição que aparece na seção se refere à definição de Estatística.
} 


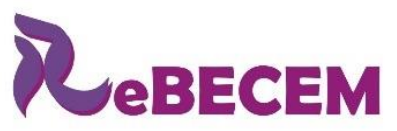

\section{Revista Brasileira de Educação em \\ Ciências e Educação Matemática}

DOI: http://dx.doi.org/10.33238/ReBECEM.2019.v.3.n.2.22439

a que tem maior índice de eficiência na produção de leite. A seção é dividida em quatro subseções, a saber: compreendendo o problema; elaborando um plano; executando um plano e realizando o retrospecto e a verificação. A organização das subseções dá condições para que na última subseção o aluno seja capaz de resolver o problema, desde que ele tenha resolvido todas as atividades propostas anteriormente.

Para os autores essa seção se faz importante pois o ser humano está inserido em um ambiente em que precisa resolver problemas constantemente, sejam eles do cotidiano, sociais, científicos ou de outra natureza (SOUZA; PATARO, 2015, p. 356).

Por fim, a seção ENEM e OBMEP é composta por sete questões, dispostas em duas páginas, todas as questões são de múltipla escolha.

Como podemos perceber tanto a organização global quanto a organização regional, não nos permitem destacar com precisão o enfoque dado ao nosso objeto de estudo: os conteúdos relacionados ao bloco Tratamento da Informação. Esse fato nos conduz a realização de uma análise mais detalhada, assim realizaremos a análise local das seções 2, 3, 4, 5, 6, e 7 destacadas na Quadro 4.

\subsection{Organização local do livro didático}

Nagamine et al., (2011) afirmam que: "essa organização permite evidenciar os objetos de estudo tratados em um determinado capítulo ou seção do livro em análise”. No presente trabalho, iremos nos dedicar nas seções relacionadas ao capítulo Tratamento da Informação, como apresentado no Quadro 4.

Quadro 4: Organização local do livro didático

\begin{tabular}{|l|l|l|l|l|l|}
\hline Seção & Subseção & Definição & Exemplos & Atividades & N de Páginas \\
\hline $\begin{array}{l}\text { Gráficos e } \\
\text { tabelas }\end{array}$ & --- & 2 & 4 & 3 \\
\hline $\begin{array}{l}\text { Construção de } \\
\text { gráficos de } \\
\text { setores }\end{array}$ & --- & --- & 1 & 2 & 2 \\
\hline $\begin{array}{l}\text { Média } \\
\text { aritmética }\end{array}$ & --- & 1 & 1 & 3 & $1 / 2$ \\
\hline $\begin{array}{l}\text { Média } \\
\text { ponderada }\end{array}$ & --- & --- & 1 & 2 & 2 \\
\hline Possibilidades & --- & --- & 2 & 7 & 4 \\
\hline Probabilidade & --- & --- & 2 & 7 & 3 \\
\hline
\end{tabular}

Fonte: dados da pesquisa

De acordo com o Quadro 4 podemos perceber que a seção Gráficos e tabelas é composta por definições, exemplos e exercícios. Esta seção inicia informando que os gráficos e tabelas estão presentes em diversos meios de comunicação, pois eles têm a 


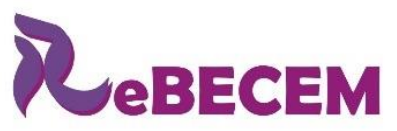

Revista Brasileira de Educação em

Ciências e Educação Matemática

DOI: http://dx.doi.org/10.33238/ReBECEM.2019.v.3.n.2.22439

potencialidade de transmitir informações de maneira simples e organizada. Na sequência, os autores definem Estatística como sendo: "a parte da matemática que estuda técnicas de obtenção, organização e análise de dados” (SOUZA; PATARO, 2015, p. 128).

Segundo Cazorla, Kataoka e Silva (2010) a Estatística é uma ciência que tem como objetivo desenvolver métodos para coletar, organizar e analisar dados. Nesse sentido, percebemos que há pontos em comum em ambas as definições. Ainda nessa seção percebemos uma fragilidade nos conceitos abordados. Os autores definem a Estatística, no entanto, não definem o que vêm a ser um gráfico e uma tabela, abordam apenas a sua importância e traz um exemplo (um de gráfico e outro de tabela) mostrando como são dispostos os dados nesses dois meios de transmissão de informação. Assim, apontamos a necessidade de uma definição do que vem a ser gráficos e tabelas, bem como alguns exemplos dos diferentes tipos de gráficos existentes. As atividades relacionadas a essa seção são todas voltadas a leitura e interpretação de tabelas, gráficos de linha e de barra.

Na seção seguinte, construção de gráfico de setores, inicia mostrando dados de uma pesquisa realizada por um site. Os dados foram utilizados para a construção de um gráfico de setor que serviu como exemplo da seção. Mais uma vez, os autores não se atentaram a definir o que é um gráfico e nem mesmo a revisar a existência de outros tipos de gráficos (conteúdo apresentado no livro do $6^{\circ}$ ano da mesma coleção).

$\mathrm{Na}$ sequência os autores apresentam os passos para a construção do gráfico de setores, a princípio o cálculo de porcentagem e na sequência o cálculo da medida do ângulo correspondente a cada porcentagem obtida no passo anterior.

Por fim, apresentam os passos para a construção do gráfico com o auxílio de régua e compasso. A seção é concluída com o gráfico de setores. São propostas duas atividades relacionadas à construção desse tipo de gráfico.

A seção média aritmética é iniciada com uma tabela mostrando quantidade de jogos realizados por um determinado time e o número de gols feitos. Posteriormente os autores apontam que com aqueles dados é possível se calcular a média de gols por jogo e apresenta como fazer essa média.

Após o exemplo, os autores apresentam a definição de Média aritmética, como sendo: "a soma de dois ou mais números divididos pela quantidade de números somados" (SOUZA; PATARO, 2017, p. 133).

No que tange à seção sobre Média ponderada a mesma se inicia com uma situação relacionada ao peso das questões de uma prova de um determinado concurso. Após a exposição da situação os autores destacam que: "podemos calcular a média ponderada 


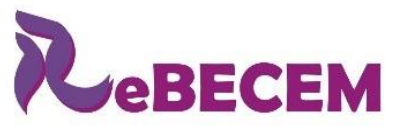

DOI: http://dx.doi.org/10.33238/ReBECEM.2019.v.3.n.2.22439
Revista Brasileira de Educação em

Ciências e Educação Matemática

(Mp) adicionando ao produto de cada nota pelo peso correspondente e dividindo o resultado pela soma dos pesos" (SOUZA; PATARO, 2017, p. 133).

A seção possibilidades também se inicia com uma situação problema referente a um consumidor em uma loja de eletrodomésticos, que dispõe de três opções de configurações de computador e duas formas de pagamento, os autores questionam ao leitor quais as possibilidades que o consumidor tem para comprar um computador, no qual o autor aborda a árvore de possibilidades e por meio dela mostra a quantidade de possibilidades que o consumidor tem para comprar o computador. Uma abordagem com uma relevância primordial para esse conteúdo, pois se trata de uma das propostas sugeridas pelo PCN para o ano destinado.

Os autores apresentam mais um exemplo seguindo a mesma linha de raciocínio e na sequência dispõem de sete atividades envolvendo o conceito de possibilidades. Destacamos que nessa seção os autores não definem: possibilidades, espaço amostral, evento e nem experimentos, termos essenciais para à compreensão do conteúdo de probabilidade.

A última seção de conteúdo, intitulada probabilidade, é iniciada com os autores abordando sobre jogos de loteria e lançamento de dados como exemplos de chance e probabilidade de ocorrência de certos resultados. Os autores apresentam um dado e em seguida trazem de forma detalhada como calcular a probabilidade de se lançar um dado e observar a face de cima do dado e o resultado ser um número par. Observamos aqui uma lacuna, que pode levar à uma dificuldade do aluno, pois, o resultado ser par é um evento do espaço amostral. A seção é concluída com uma sequência de sete atividades relacionadas ao conteúdo de probabilidade.

No capítulo analisado os autores abordam sobre: gráficos e tabelas, construção de gráficos de setores, média aritmética e média ponderada, possibilidade e por fim, probabilidade. Destacamos de acordo com Quadro 1 para o terceiro ciclo ( $6^{\circ}$ e $7^{\circ}$ ano) que os alunos devem apresentar as seguintes habilidades: leitura, construção e interpretação de dados expressos em tabelas e gráficos de barra, setor e pictogramas.

Apesar da explanação do autor, percebemos que ainda existe uma lacuna ao que se refere à associação do tipo de gráfico adequado para os tipos de variáveis: qualitativas e quantitativas. Uma vez que, esses conceitos não foram apresentados.

No que se refere aos conteúdos conceituais e procedimentais referentes ao espaço amostral e definição de probabilidade podemos perceber por meio do Quadro 1 que deve ser discutido a construção do espaço amostral e indicação de possibilidade de sucesso de 
DOI: http://dx.doi.org/10.33238/ReBECEM.2019.v.3.n.2.22439

um evento pelo uso da razão. No entanto, apontamos que no capítulo analisado, as discussões sobre as definições de espaço amostral, evento, experimentos aleatórios e determinísticos não foram abordados, e classificamos essa discussão como de suma importância para a aprendizagem do conceito de probabilidade e possibilidades.

\section{Conclusão}

Entendemos que o livro didático é o principal e, muitas vezes, o único recurso de trabalho do professor. Assim, um texto em que os conceitos, os exemplos e as atividades sejam apresentados de forma apropriada permitirá uma melhor qualidade do ensino e a formação adequada do aluno.

Da análise realizada, (global, regional e local) percebemos que ainda é necessário percorrer um longo caminho para que os conteúdos relacionados ao bloco Tratamento da Informação e a unidade temática Probabilidade e Estatística sejam trabalhados e valorizados como sugerem os PCN e a BNCC, visto que nossa análise mostrou um capítulo com algumas lacunas em relação ao que deve ser trabalhado no $7^{\circ}$ ano.

Dentre as competências propostas pelos PCN e pala BNCC, destacamos a contextualização sociocultural como forma de aproximar o aluno da realidade e fazê-lo vivenciar situações próximas que lhe permitam reconhecer a diversidade que o cerca e reconhecer-se como indivíduo capaz de ler e atuar nessa realidade. Diante do analisado, percebemos que o livro didático possui lacunas no que se refere a essa contextualização, aponta indicativos de contextualização, mas não se abre a discussão. Além disso, nem sempre as contextualizações condizem com a realidade dos estudantes o que pode influenciar na leitura crítica dos alunos a respeito de sua sociedade.

\section{Referências}

BRASIL. Secretaria de Educação Fundamental. Parâmetros Curriculares Nacionais: introdução aos parâmetros curriculares nacionais / Secretaria de Educação Fundamental. Brasília: MEC/SEF, 1997.

BRASIL. Secretaria de Educação Fundamental. Parâmetros Curriculares Nacionais: Matemática. Brasília: MEC/SEF, 1998.

BRASIL. Programa Nacional do Livro Didático 2017. Guia de livros didáticos ensino fundamental anos finais. Brasília: MEC/Secretaria de Educação Fundamental, Matemática, 2017a. 
DOI: http://dx.doi.org/10.33238/ReBECEM.2019.v.3.n.2.22439

BRASIL. Secretaria de Educação Fundamental. Base Nacional Comum Curricular. Brasília: MEC/SEF, 2017b.

CAZORLA, I; SANTANA, E. Do Tratamento da Informação ao Letramento Estatístico. 1. ed. Itabuna: Via Litterarum, 2010.

CAZORLA, I. M.; KATAOKA, V. Y.; SILVA, C. B. Trajetória e Perspectivas da Educação Estatística no Brasil: uma olhar a partir do GT12. In: LOPES, C. E.; COUTINHO, C. Q. S.; ALMOULOUD, S. (org.). 1. ed. Estudos e Reflexões em Educação Estatística. Campinas, SP: Mercado de Letras, 2010. p. 19 - 44.

CHARMAZ, K. A construção da teoria fundamentada. Tradução de Joice Elias Costa. 1. ed. Porto Alegre: Artmed, 2009.

FIORENTINI, D. LORENZATO, S. Investigação em educação matemática. 2. ed. Campinas: Autores Associados, 2007.

GARFIELD, J.; GAL, I. Teaching and assessing statistical reasoning. In: STIFF, L. (ed.). Developing mathematical reasoning in grades K-12. Reston: National Council Teachers of Mathematics, 1999.

HENRIQUES, A.; NAGAMINE, A.; NAGAMINE, C. M. L. Reflexões Sobre Análise Institucional: o caso do ensino e aprendizagem de integrais múltiplas. Bolema, Rio Claro, v. 26, p. 44-69, 2012.

JACOBINI, O. R.; WODEWOTZKI, M. L. L.; CAMPOS, C.R. Educação Estatística: teoria e prática em ambientes de modelagem matemática. 1. ed. Belo Horizonte: Autêntica Editora, 2011.

LOPES, C. E. Os desafios para educação estatística no currículo de matemática. In: LOPES, C. E.; COUTINHO, C. de Q. e S; ALMOULOUD, S. A. (org.) Estudos e reflexões em educação estatística. 1. ed. Campinas: Mercado de letras, 2010.

NAGAMINE, C. M. L. et al. Análise praxeológica dos Passeios Aleatórios da Mônica. Bolema, Rio Claro, v. 24, p. 451-472, 2011.

SOUZA, J.; PATARO, P. M. Vontade de saber Matemática, $\mathbf{7}^{\mathbf{0}}$ ano. 3. ed. São Paulo: FTD, 2015.

VIALI, L.; OLIVEIRA, P. I. F. de. Uma análise de conteúdos de Probabilidades em livros didáticos do Ensino Médio. In: LOPES, C. E. L.; COUTINHO, C. de Q. S.; ALMOULOUD, S. (org). Estudos e reflexões em Educação Estatística. Campinas: Mercado de Letras, 2010.

Recebido em: 19 de maio de 2019.

Aceito em: 22 de agosto de 2019. 